\title{
Deaths due to solvent inhalation/glue sniffing- effective extraction from blood and viscera by direct distillation as isopropanol azeotrope
}

\author{
Poorvisha Ravi $^{1^{*}}$, Srividya Srinivasan ${ }^{2}$, A Visalakshi $^{3}$, M Srinivasan $^{4}$ \\ ${ }^{1}$ Scientific Officer, ${ }^{2}$ Assistant Director, ${ }^{3}$ Deputy Director, ${ }^{\mathbf{4}}$ Director, ${ }^{\mathbf{1 - 4}}$ Dept. of Forensic Sciences, ${ }^{\mathbf{1 - 4}} 30 \mathrm{~A}$ Kamarajar Salai, Mylapore, Tamil \\ Nadu, Chennai, India \\ * Corresponding Author: Poorvisha Ravi \\ Email: poorvisharavi1990@gmail.com
}

\begin{abstract}
"Glue sniffing" deaths are on the rise due to easy availability of products containing industrial solvents such as toluene and xylene, therefore necessitating their detection in post mortem blood and viscera. In such cases where analyte quantity is low, direct instrumental analysis, such as Head Space Gas Chromatography ${ }^{1}$, may not be feasible. In two separate cases of death, one due to "glue sniffing" and another due to accidental toluene inhalation respectively, a simple method for effective extraction from post mortem blood and viscera by direct distillation as isopropanol azeotropes and subsequent screening with GC-FID has been described.
\end{abstract}

Keywords: Glue sniffing, solvent inhalation death, toluene inhalation, xylene inhalation.

\section{Introduction}

Solvent inhalation may occur due to deliberate intoxication through "glue sniffing" or due to accidental exposure in workplace.

In one case, a 29 year old male- a known "glue sniffing" addict- was found dead on the footpath. No samples of intoxicants from the scene were sent. Xylene was detected in his liver and blood samples after subsequent toxicological analysis using this method.

In another case, two male labourers aged 57 and 37 years were found dead in a closed chamber while doing sealing work with rubber solution. Upon reconstruction of the scene, it was found that a large glass container of thinner (toluene) used along with the rubber solution had broken inside the chamber, resulting in the two workers being fatally exposed to the toxic vapours of toluene. Along with the blood and visceral organs of the deceased, samples of the rubber solution and thinner obtained from the scene were sent for toxicological analysis. Toluene was detected using the same method as above.

Due to the higher boiling ranges of toluene and xylene, extraction by direct distillation of post mortem samples as azeotropic mixture of isopropanol was found to be more effective, as compared to steam distillation.

\section{Absorption, metabolism and effects of toluene and xylene}

Toluene has been detected in human arterial blood in 10 seconds post inhalation. ${ }^{2}$ About $80 \%$ of absorbed toluene is metabolized in the liver to Benzoic acid, which is conjugated with glycine to form Hippuric acid, a water soluble compound, which is excreted primarily in urine. ${ }^{3}$ Toluene is highly lipid soluble and accumulates in adipose tissue, tissues with high fat content and highly vascularized tissues. Highest concentrations are found in the liver, kidney, brain and blood. Its initial half life in whole blood ranges between 3-6 hours and terminal phase half life is 72 hours. Three fatalities from acute toluene inhalation were found to have blood concentrations 50,60 and $79 \mathrm{mg} / \mathrm{L}$. In eight reported fatalities, blood concentrations of toluene ranged from $10-48 \mathrm{mg} / \mathrm{L} .{ }^{4}$ Acute toluene exposure causes CNS depression, cardiac arrhythmias and sudden death depending upon the concentration and exposure. ${ }^{5}$

Commercial xylene is often a mixture of $\mathrm{o}-, \mathrm{m}$ - and $\mathrm{p}$ xylenes. It is primarily metabolized in the liver by oxidation of a methyl group and conjugation with glycine to yield methyl hippuric acid, which is excreted in the urine. Acute xylene exposure causes irritation of the skin, eyes and mucosa and CNS depression. ${ }^{5}$ Extreme over exposure can result in pulmonary edema. ${ }^{6}$ Death occurs at exposure above $10,000 \mathrm{ppm}^{7}$ The biological half-life as assessed by urinary metabolite excretion after termination of inhalational exposure was 1.5 hours. $^{8}$

Approximately $90 \%$ of xylene distributed by the blood is bound to serum proteins. After human ingestion of a lethal amount of xylene, levels of chemical in the blood, stomach, and intestine were $110 \mathrm{mg} / \mathrm{L}, 8800 \mathrm{mg} / \mathrm{L}$, and $33,000 \mathrm{mg} / \mathrm{L}$, respectively. ${ }^{9}$

Ethanol enhanced significantly the blood levels of inhaled toluene, ethyl benzene, or m-xylene. ${ }^{10}$

\section{Azeotropy in distillation}

The principle of azeotropy, wherein, the addition of one or more solvents results in an altered boiling range of the mixture, was exploited to effectively extract solvents from post mortem samples. In minimum boiling azeotropic mixtures, the azeotrope boils at a temperature lower than that of the individual components. The boiling points of water, toluene and isopropanol are $100,82.5$ and $110.6^{\circ} \mathrm{C}$ respectively, but that of an azeotropic mixture (\% by weight) of water (13.1), isopropanol (38.2) and toluene (48.7) is $76.3^{\circ} \mathrm{C}$. Azeotropes of water, isopropanol and xylene $\left(138.4^{\circ} \mathrm{C}\right)$ have boiling range between $60-75^{\circ} \mathrm{C} .{ }^{11}$ 


\section{Materials and Methods}

About $25 \mathrm{ml}$ of blood or liver homogenate was taken and 15 $\mathrm{ml}$ of isopropanol was added to it. The sample was subjected to distillation using an Automatic Distillation Apparatus (AD-86 5G2) within the temperature range of 60$75^{\circ} \mathrm{C}$. The conditions can also be replicated in manual distillation.

First few drops (3-5) of the distillate were collected and analysed using GC-FID. The samples were also suitable for screening with UV spectrophotometry.

Along with case articles, blank and spiked samples of blood and liver were also subjected to the same treatment to be treated as negative and positive controls respectively.

Mixtures of varying concentrations of isopropanol with xylene and toluene respectively were used as working standards and for calibration.

\section{GC-FID Make}

Agilent Technologies 7683B Series

\section{Column}

Type: Pona column 51972

Diameter: $200.0 \mu \mathrm{m}$

Film thickness: $0.50 \mu \mathrm{m}$

Length: $50.0 \mathrm{~m}$

\section{Specifications}

Inlet temperature: $250.0^{\circ} \mathrm{C}$

FID set point: $280.0^{\circ} \mathrm{C}$

Carrier gas: Helium

Make up: Hydrogen

Flame: Hydrogen and air

Total run time: $37.00 \mathrm{~min}$

Pressure: 29.50 bar

Void time: $3.688 \mathrm{~min}$

Table 1

\begin{tabular}{|c|c|c|c|}
\hline $\begin{array}{c}\text { Oven } \\
\text { temperature }\end{array}$ & $\begin{array}{c}\text { Rate } \\
\left({ }^{\circ} \mathbf{C} / \mathbf{m i n}\right)\end{array}$ & $\begin{array}{c}\text { Final } \\
\text { temperature }\left({ }^{\circ} \mathbf{C}\right)\end{array}$ & $\begin{array}{c}\text { Hold time } \\
(\mathbf{m i n})\end{array}$ \\
\hline Initial & - & 50.0 & 2.00 \\
\hline Ramp 1 & 15.0 & 200.0 & 10.00 \\
\hline Ramp 2 & 10.0 & 250.0 & 10.00 \\
\hline
\end{tabular}

\section{Results and conclusion}

Toluene and Xylene were detected in the separate azeotropic mixture distillates along with Isopropanol which also served as an internal standard. Steam distillates of the samples did not yield satisfactory detection with either GCFID or UV spectrophotometry.

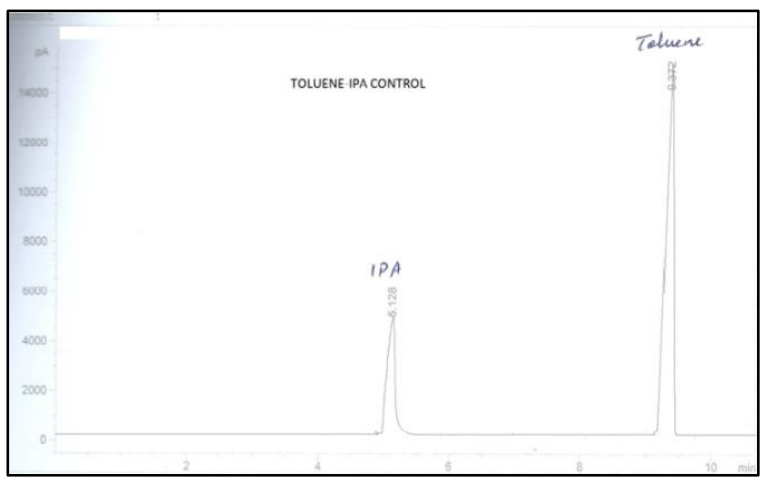

Fig. 1: Toluene - isopropanol control mixture GC-FID chromatogram

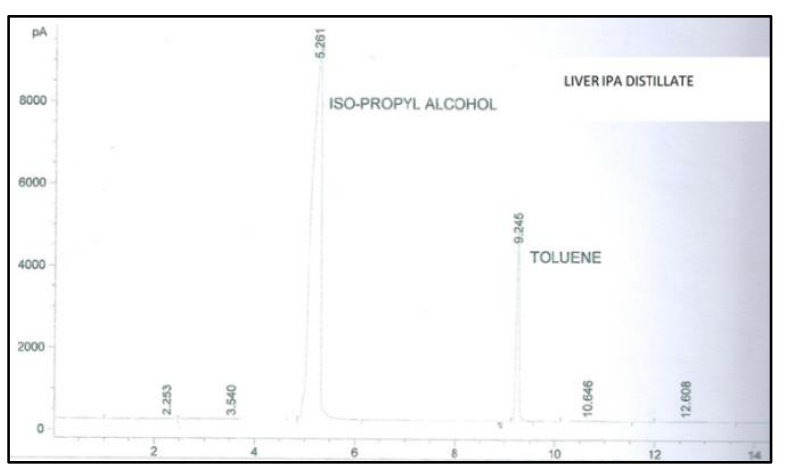

Fig. 2: Liver homogenate - isopropanol distillate GC-FID chromatogram

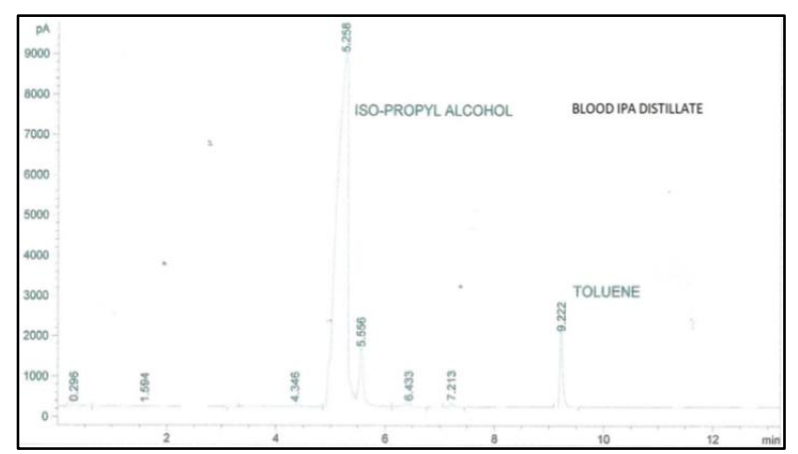

Fig. 3: Blood - isopropanol distillate GC-FID chromatogram

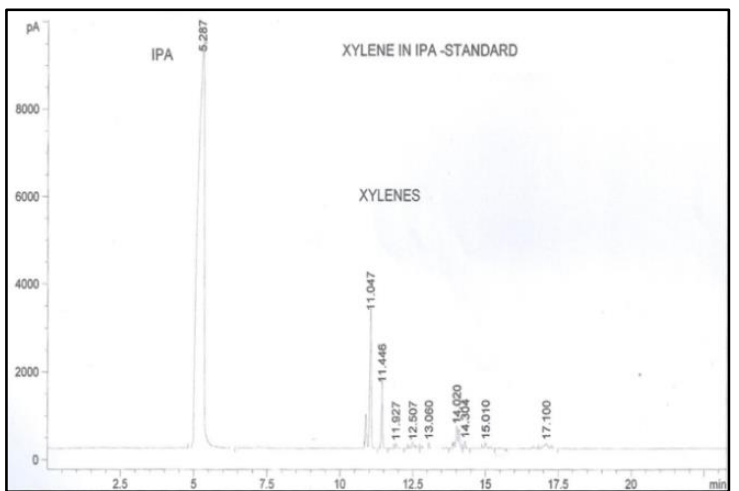

Fig. 4: Xylenes - isopropanol control mixture GC-FID chromatogram 


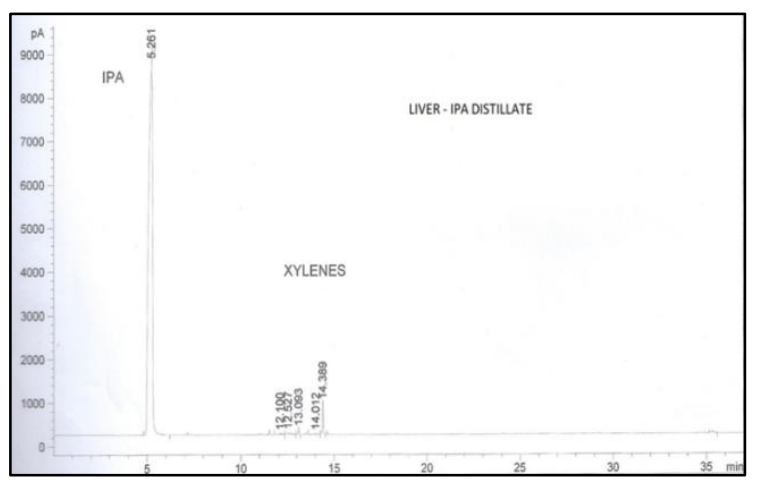

Fig. 5: Liver homogenate - isopropanol distillate GC-FID chromatogram

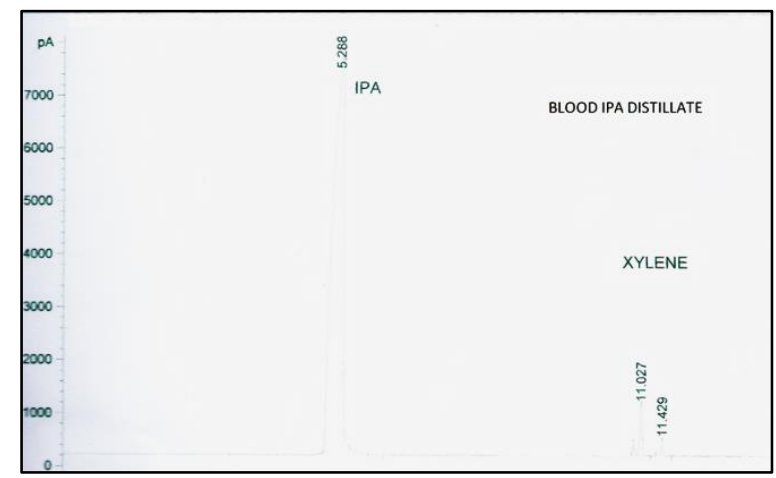

Fig. 6: Blood - isopropanol distillate GC-FID chromatogram

\section{Discussion}

The quantity of solvent available in post mortem samples is very low in cases of solvent inhalation, especially in cases of "glue sniffing". In conjunction with the higher boiling ranges of these solvents, and their relative insolubility in water, this method proved to be more effective for sample preparation than steam distillation.

Azeotropic mixtures of liquids retain their relative concentration in vapour state as well. Thus, by altering the proportion of isopropanol with respect to what can be expected from the sample, analytes can be successfully concentrated in the distillate, thus enabling successful detection.

Hence, this extraction method of solvents from blood and viscera by distillation as azeotrope is effective and also enables handy, easy, cost effective, replicable and rapid sample preparation for successful detection with various instrumental methods.

Source of Funding: None.

Conflict of Interest: None.

\section{References}

1. Tranthim-Fryer, D., Hansson, R., and Norman, K., "Headspace/Solid-Phase Microextraction/Gas ChromatographyMass Spectrometry: A Screening Technique for the Recovery and Identification of Volatile Organic Compounds (VOC's) in Postmortem Blood and Viscera Samples. J Forensic Sci 2001;46(4):934-46, https://doi.org/10.1520/JFS15073J. ISSN 0022-1198 Surname A and Surname B 2009 Journal Name 23 544.

2. Health Protection Agency (HPA) Toluene Toxicological Overview.

2007,http://www.hpa.org.uk/web/HPAwebFile/HPAweb_C/119 4947395545.

3. International Program on Chemical Safety - Basic Analytical Toxicology - Flanagan R.J., Braithwaite R.A., Brown S.S., Widdop B., F.A. de Wolff - World Health Organisation, 2016.

4. https://www.wsp.wa.gov/breathtest/docs/webdms/DRE_Forms/ Publications/drug/Human_Performance_Drug_Fact_SheetsNHTSA.pdf

5. Ellenhorn's Medical Toxicology - Diagnosis and Treatment of Human Poisoning - Second Edition - Page no.1494

6. Kandyala R, Raghavendra SP, Rajasekharan ST. Xylene: An overview of its health hazards and preventive measures. J Oral Maxillofac Pathol 2010;14(1):1-5. doi: 10.4103/0973029X.64299. PubMed PMID: 21180450; PubMed Central PMCID: PMC2996004.

7. National Research Council (US) Committee on Acute Exposure Guideline Levels. Acute Exposure Guideline Levels for Selected Airborne Chemicals: Volume 9. Washington (DC): National Academies Press (US); 2010. 6, Xylenes Acute Exposure Guideline Levels.Available from: https://www.ncbi.nlm.nih.gov/books/NBK208153/

8. Senczuk W \& Orlowski J 81978) Absorption of m-xylene vapours through the respiratory tract and excretion of $\mathrm{m}$ methylhippuric acid in urine. Br J Ind Med 35:50-55.

9. https://rais.ornl.gov/tox/profiles/xylene.html\#t 42

10. https://pdfs.semanticscholar.org/42d2/12e0cc9d6e6d6c236506e 5576ce80e06ea19.pdf

11. http://www.ddbst.com/ddb.html

How to cite this article: Ravi $\mathrm{P}$, Srinivasan S, Visalakshi A, Srinivasan M.Deaths due to solvent inhalation/glue sniffingEffective extraction from blood and viscera by direct distillation as isopropanol azeotrope. Int J Forensic Med Toxicol Sci 2019;4(4):149-151. 